\title{
Patterns of borrowing to finance out-of-pocket prescription drug costs in Canada: a descriptive analysis
}

\author{
Ashra Kolhatkar MPH, Lucy Cheng MSc, Steven G. Morgan PhD, Laurie J. Goldsmith PhD, \\ Irfan A. Dhalla MD MSc, Anne M. Holbrook MD PharmD, Michael R. Law PhD
}

Abstract

Background: Out-of-pocket drug costs lead many Canadians to engage in cost-related nonadherence to prescription medications, but our understanding of other consequences such as borrowing money remains incomplete. In this descriptive study, we sought to quantify the frequency of borrowing to pay for prescription drugs in Canada and characteristics of Canadians who borrowed money for this purpose.

Methods: In partnership with Statistics Canada, we designed and administered a cross-sectional rapid-response module in the Canadian Community Health Survey administered by telephone to Canadians aged 12 years or more between January and June 2016. We restricted our analyses to participants who responded to the question regarding borrowing money to pay for prescription drugs and used logistic regression to identify characteristics associated with borrowing.

Results: A total of 28091 Canadians responded to the survey (overall response rate 61.8\%). The weighted proportion of respondents who reported having borrowed money to pay for prescription drugs in the previous year was $2.5 \%$ (95\% confidence interval $2.2 \%-2.8 \%$ ), an estimated 731000 Canadians. The odds of borrowing were higher among younger adults, people in poor health and people lacking prescription drug insurance. Other factors associated with increased adjusted odds of borrowing were having 2 or more chronic conditions, low household income and higher out-of-pocket prescription drug costs.

Interpretation: Many Canadians reported borrowing money to pay for out-of-pocket prescription drug costs, and borrowing was more prevalent among already vulnerable groups that also report other compensatory behaviours to address challenges in paying for prescription drugs. Future research should investigate policy responses intended to increase equity in access to prescription drugs.

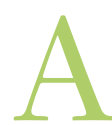

11 Canadian residents are insured for medically necessary hospital care and physician services, without out-of-pocket charges at the point of care. However, this insurance excludes prescription drugs used outside of hospitals. Although many Canadians have some form of prescription drug insurance through work-related benefits or public programs, others lack any drug coverage. ${ }^{1}$ In addition, Canadians with prescription drug insurance still often have to bear some or all of the costs of their drugs owing to insurance plan deductibles, copayments and gaps in insurance whereby some drugs are not covered., ${ }^{1,2}$ The out-of-pocket pharmaceutical costs borne by uninsured or underinsured Canadians can be substantial and tend to disproportionately affect potentially vulnerable populations, ${ }^{3-6}$ including children, older people, ethnic minorities and those who are socioeconomically disadvantaged. ${ }^{7,8}$ The consequences of high out-ofpocket costs vary. Patients have reported engaging in compensatory behaviours including cost-related nonadherence to prescription medications, ${ }^{6,9,10}$ which affects about $8 \%$ of Canadians with a drug prescription. ${ }^{11-14}$ Patients also make trade-offs against spending in other areas of the household budget to be able to afford prescription drugs. ${ }^{6,9,15-17}$

Patients have also reported borrowing money, including increasing credit card debt, to compensate for high drug costs and borrowing money from family and friends as a way to cope with high health care costs. ${ }^{10,18-21}$ However, most of this evidence is from the United States, which has a markedly different health insurance system and different levels of out-of-pocket

Competing interests: Michael Law has consulted for Health Canada and has acted as an expert witness for the Attorney General of Canada. Anne Holbrook is a therapeutics expert and drug policy consultant for the Ontario public drug programs, the Canadian Agency for Drugs and Technologies in Health and Hamilton hospitals. No other competing interests were declared.

This article has been peer reviewed.

Correspondence to: Michael Law, michael.law@ubc.ca

CMAJ Open 2018. DOI:10.9778/cmajo.20180063 
drug costs from Canada. Furthermore, few studies distinguish between borrowing to pay for medication costs specifically and health care costs in general. In addition, existing studies have tended to focus on patients with specific high-cost illnesses rather than the general population. ${ }^{18,20-22}$ In sum, little is known about borrowing to finance prescription medicine in Canada. Therefore, we sought in this descriptive study to quantify the frequency of borrowing to pay for prescription drugs in Canada and to identify predictors of such activity.

\section{Methods}

\section{Data sources}

The data for this study came from a cross-sectional rapidresponse module in the Canadian Community Health Survey administered by telephone to Canadians aged 12 years or more between January and June 2016. In brief, our team collaborated with Statistics Canada to design a module of questions exploring the consequences of out-of-pocket drug charges for patients. The questions in the module drew on validated questions in the literature, previous iterations of the Canadian Community Health Survey and previous qualitative work by our team. 5,6,9,10,12,17,23,24 The questions were vetted and underwent qualitative testing by Statistics Canada in both French and English. The module ${ }^{25}$ was administered by Statistics Canada in accordance with Canadian Community Health Survey guidelines. ${ }^{26}$ Respondents were asked a range of sociodemographic and health questions, including whether they had borrowed money to pay for prescription medicines: "In the last 12 months, have you or anyone else in the household ever had to borrow money to pay for your prescriptions?" Following rigorous pilot testing conducted by Statistics Canada, the phrasing of this question specifically excluded examples of kinds of borrowing (e.g., from friends or family, on a credit card) to minimize confusion for the respondent. We restricted our analyses in this study to participants who responded to this question.

\section{Statistical analysis}

We calculated the total number of respondents and nationally representative estimates of the weighted proportions of the population reporting having to borrow money to pay for prescription drugs. We used multivariate logistic regression to investigate the factors associated with reporting having borrowed money to pay for prescription drugs. We included variables previously shown to be associated with difficulty paying for medications: sex, age, self-reported health status, number of chronic conditions (including arthritis, chronic obstructive pulmonary disease, diabetes, cancer, heart disease, high blood pressure and mood disorders), ethnicity, household income, education and prescription drug insurance status. ${ }^{5,6}$

We used step-wise multiple imputation methods to fill in missing data: we first imputed values for the variable missing the most data and then used the imputed values to the next highest, and so on until all missing variables had been imputed. ${ }^{27,28}$ Once the imputation for each variable was complete, we recombined the data sets to incorporate the adjust- ments to variance. To incorporate the complex sampling design of the Canadian Community Health Survey into our population estimates, we used survey weights provided by Statistics Canada and bootstrapping to calculate confidence intervals (CIs). ${ }^{29}$

\section{Ethics approval}

This study was approved by the University of British Columbia Behavioural Research Ethics Board.

\section{Results}

\section{Descriptive characteristics}

Responses were collected from 28091 people, with a combined Canada-wide response rate of $61.8 \%$. Of the respondents, 572 (2.0\% of the total sample) were excluded because they responded "Don't know" or refused to answer the question on borrowing, leaving a sample of 27519 respondents. Data on 1 or more variables were missing for 1390 respondents $(5.0 \%)$ across 4 variables (self-reported health status, out of pocket drug costs, education and prescription drug insurance), with a maximum of $2.4 \%$ of the total sample for any single variable (out-of-pocket drug costs). Table 1 presents weighted proportions of the total population: $50.7 \%$ of the respondents were female, $48.6 \%$ were less than age 45 years, $11.1 \%$ reported having fair or poor health, $20.3 \%$ had an annual household income of less than $\$ 40000$, and $20.3 \%$ reported having no prescription drug insurance.

\section{Borrowing to finance out-of-pocket prescription drug costs}

The weighted proportion of respondents who reported having borrowed money to pay for prescription medications in the previous year was $2.5 \%$ (95\% CI $2.2 \%-2.8 \%$ ) (Table 1 ). At the population level, this is equivalent to an estimated 731000 Canadians (95\% CI 639 000-824 000). Compared to respondents who did not report borrowing money to pay for prescription medications, those who reported borrowing tended to be younger and in poorer health, to have more chronic conditions, and to report government or no prescription drug insurance.

Figure 1 provides an illustration of some of the differences in rates of borrowing money to pay for prescription drugs across different groups in our sample. Respondents aged 19-34 years had the highest rate of borrowing (3.7\%, 95\% CI 2.9-4.4) (Figure 1, A). Respondents with a household income of less than $\$ 20000$ a year had more than twice the rate of borrowing $(6.6 \%, 95 \%$ CI 5.0-8.3) than those earning $\$ 40000$ a year or more (Figure 1, B). Respondents who lacked any kind of prescription drug insurance had the highest rate of borrowing $(4.6 \%, 95 \%$ CI 3.5-5.7), and those with employer-based drug insurance had the lowest rate of borrowing (1.3\%, 95\% CI 1.0-1.6) (Figure 1, C). As annual outof-pocket costs on prescription drugs increased, respondents were more likely to report having borrowed money to pay for prescription drugs (\$501-\$1000: 9.5\%, 95\% CI 6.9-12.0; > \$1000: 11.5\%, 95\% CI 8.6-14.3) (Figure 1, D). 
Table 1: Characteristics and prevalence of patients who reported having to borrow money to pay for prescription drugs among respondents to the Canadian Community Health Survey between January and June 2016

\begin{tabular}{|c|c|c|c|c|}
\hline \multirow[b]{2}{*}{ Variable } & \multirow[b]{2}{*}{$\begin{array}{l}\text { No. of } \\
\text { respondents* }\end{array}$} & \multicolumn{3}{|c|}{ Value $(95 \% \mathrm{Cl})$} \\
\hline & & $\begin{array}{l}\text { Weighted proportion } \\
\text { of total population } †\end{array}$ & $\begin{array}{l}\text { Weighted proportion who } \\
\text { report borrowing }=1 \dagger\end{array}$ & $\begin{array}{l}\text { Weighted proportiont (within } \\
\text { those with borrowing }=1 \text { ) }\end{array}$ \\
\hline Total & 27519 & $100.0(100.0-100.0)$ & $2.5(2.2-2.8)$ & $100.0(100.0-100.0)$ \\
\hline \multicolumn{5}{|l|}{ Sex } \\
\hline Female & 13949 & $50.7(50.5-50.9)$ & $3.2(2.7-3.7)$ & $65.2(59.5-70.8)$ \\
\hline Male & 13570 & $49.3(49.1-49.5)$ & $1.7(1.4-2.1)$ & $34.8(29.2-40.5)$ \\
\hline \multicolumn{5}{|l|}{ Age, yr } \\
\hline $12-18$ & 2372 & $8.6(8.3-8.9)$ & $1.8(1.1-2.5)$ & $6.1(3.8-8.5)$ \\
\hline $19-34$ & 6954 & $25.3(25.0-25.6)$ & $3.7(2.9-4.4)$ & $37.6(31.7-43.4)$ \\
\hline $35-44$ & 4045 & $14.7(14.2-15.2)$ & $2.4(1.5-3.3)$ & $14.4(9.6-19.2)$ \\
\hline $45-54$ & 4667 & $17.0(16.2-17.7)$ & $2.3(1.5-3.1)$ & $15.7(11.0-20.5)$ \\
\hline $55-64$ & 4447 & $16.2(15.6-16.7)$ & $2.2(1.4-3.0)$ & $14.2(9.6-18.7)$ \\
\hline $65-74$ & 3156 & $11.5(11.1-11.8)$ & $1.9(1.2-2.7)$ & $9.0(5.8-12.3)$ \\
\hline$\geq 75$ & 1877 & $6.8(6.5-7.1)$ & $1.1(0.6-1.6)$ & $3.0(1.6-4.4)$ \\
\hline \multicolumn{5}{|l|}{ Self-reported health status } \\
\hline Excellent & 6591 & $24.0(23.1-24.9)$ & $0.6(0.3-0.8)$ & $5.5(3.1-7.9)$ \\
\hline Very good & 10350 & $37.6(36.7-38.5)$ & $1.3(0.9-1.8)$ & $20.5(15.0-26.0)$ \\
\hline Good & 7510 & $27.3(26.4-28.2)$ & $3.2(2.5-4.0)$ & $35.9(29.8-41.9)$ \\
\hline Fair & 2213 & $8.0(7.5-8.6)$ & $6.4(5.0-7.8)$ & $20.8(16.4-25.2)$ \\
\hline Poor & 856 & $3.1(2.8-3.4)$ & $13.8(10.1-17.4)$ & $17.4(13.0-21.7)$ \\
\hline \multicolumn{5}{|l|}{ No. of chronic conditions } \\
\hline 0 & 13927 & $50.6(49.7-51.6)$ & $0.9(0.7-1.2)$ & $18.6(14.0-23.3)$ \\
\hline 1 & 7147 & $26.0(25.1-26.8)$ & $2.7(2.0-3.4)$ & $28.1(22.4-33.9)$ \\
\hline 2 & 3514 & $12.8(12.2-13.4)$ & $3.6(2.6-4.6)$ & $18.6(13.8-23.4)$ \\
\hline 3 & 1723 & $6.3(5.9-6.7)$ & $5.9(4.3-7.5)$ & $15.0(11.1-18.8)$ \\
\hline$\geq 4$ & 1208 & $4.4(4.0-4.8)$ & $11.1(8.6-13.5)$ & $19.7(15.7-23.6)$ \\
\hline \multicolumn{5}{|l|}{ Total household income, $\$$} \\
\hline$<20000$ & 1885 & $6.9(6.4-7.3)$ & $6.6(5.0-8.3)$ & $18.5(14.2-22.7)$ \\
\hline $20000-39999$ & 3690 & $13.4(12.8-14.0)$ & $5.1(4.0-6.1)$ & $27.6(22.4-32.8)$ \\
\hline $40000-59999$ & 3833 & $13.9(13.3-14.6)$ & $2.9(1.9-3.8)$ & $16.2(11.6-20.8)$ \\
\hline $60000-79999$ & 3577 & $13.0(12.3-13.7)$ & $2.1(1.3-2.9)$ & $11.1(7.2-15.0)$ \\
\hline $80000-99999$ & 3214 & $11.7(11.0-12.3)$ & $1.8(1.2-2.5)$ & $8.7(5.7-13.9)$ \\
\hline 100 000-149999 & 5501 & $20.0(19.2-20.8)$ & $1.2(0.6-1.7)$ & $9.6(5.2-13.9)$ \\
\hline$\geq 150000$ & 5818 & $21.1(20.3-22.0)$ & $1.0(0.5-1.5)$ & $8.4(4.5-12.4)$ \\
\hline \multicolumn{5}{|l|}{ Education } \\
\hline Less than secondary school & 5209 & $18.9(18.3-19.6)$ & $3.0(2.3-3.6)$ & $22.9(18.4-27.5)$ \\
\hline Secondary school & 6445 & $23.4(22.6-24.3)$ & $2.7(2.0-3.4)$ & $25.6(19.9-31.3)$ \\
\hline Postsecondary school & 15865 & $57.7(56.7-58.6)$ & $2.2(1.8-2.6)$ & $51.5(45.7-57.2)$ \\
\hline \multicolumn{5}{|l|}{ Prescription drug insurance } \\
\hline Employer plan & 14855 & $54.0(53.0-55.0)$ & $1.3(1.0-1.6)$ & $29.0(23.4-34.6)$ \\
\hline Association plan & 2284 & $8.3(7.8-8.8)$ & $2.1(1.0-3.2)$ & $7.1(3.8-10.4)$ \\
\hline Government plan & 4802 & $17.5(16.8-18.1)$ & $3.7(3.0-4.3)$ & $26.1(21.3-30.9)$ \\
\hline None & 5578 & $20.3(19.5-21.1)$ & $4.6(3.5-5.7)$ & $37.9(31.2-44.5)$ \\
\hline \multicolumn{5}{|c|}{ Out-of-pocket prescription drug spending in prior year, $\$$} \\
\hline 0 & 13575 & $49.3(48.4-50.3)$ & $0.2(0.1-0.4)$ & $4.3(1.4-7.2)$ \\
\hline $1-200$ & 8759 & $31.8(31.0-32.7)$ & $2.6(2.1-3.2)$ & $33.9(28.2-39.6)$ \\
\hline $201-500$ & 2862 & $10.4(9.9-10.9)$ & $6.4(4.8-7.9)$ & $26.4(20.8-32.0)$ \\
\hline $501-1000$ & 1406 & $5.1(4.8-5.5)$ & $9.5(6.9-12.0)$ & $20.0(15.1-25.0)$ \\
\hline$>1000$ & 916 & $3.3(3.0-3.7)$ & $11.5(8.6-14.3)$ & $15.4(11.7-19.0)$ \\
\hline $\begin{array}{l}\text { Note: } \mathrm{Cl}=\text { confidence interval. } \\
\text { *Numbers sum up slightly differently fro } \\
\text { †Calculated with the use of survey wei } \\
\text { individual respondent. }\end{array}$ & $\begin{array}{l}\text { total number owi } \\
\text { orovided by Statisti }\end{array}$ & $\begin{array}{l}\text { rounding. } \\
\text { anada, which correspond }\end{array}$ & Imber of people in the entire $p$ & tion who are represented by each \\
\hline
\end{tabular}


A

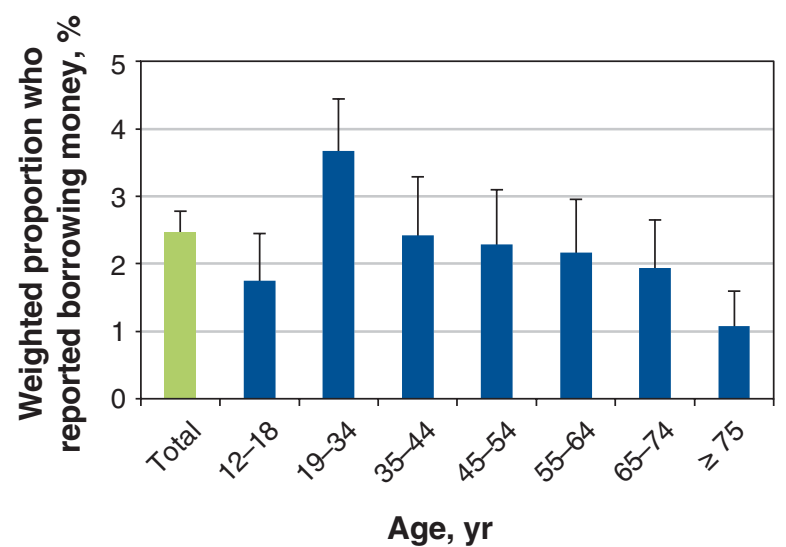

C

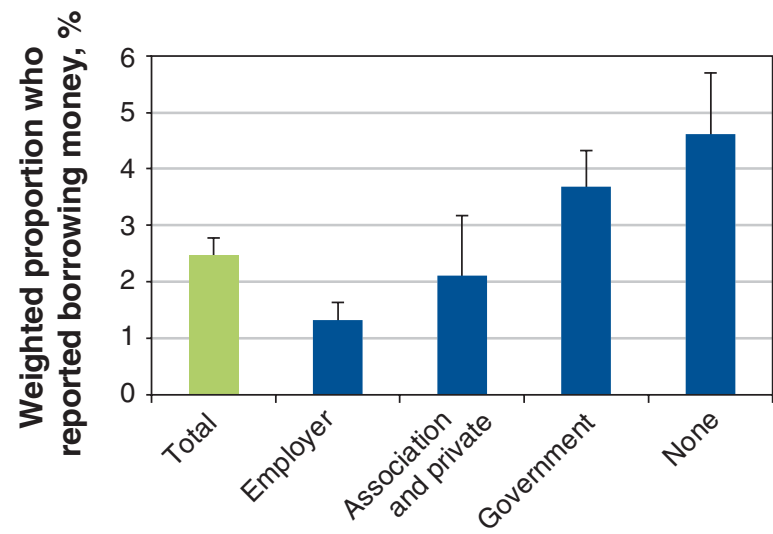

Prescription drug insurance plan type
B

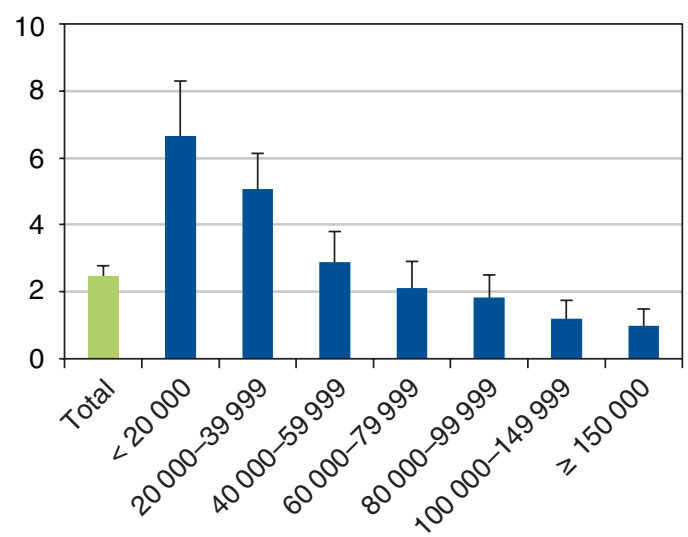

Annual household income, \$

D

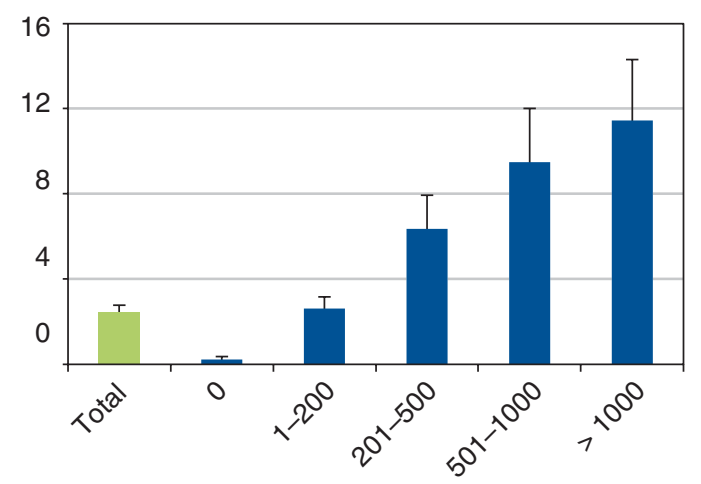

Annual out-of-pocket prescription drug expenses, \$

Figure 1: Weighted proportion of respondents who reported having borrowed money to pay for prescription drugs in the previous year, by age $(A)$, annual household income (B), prescription drug insurance plan (C) and annual out-of pocket-expenses on prescription drugs (D). "Total" bar indicates the estimated national rate of borrowing. Error bars indicate $95 \%$ confidence interval.

Our multivariate logistic regression model showed that younger age was associated with higher odds of borrowing to pay for prescription medications. After we controlled for other factors (including insurance status and size of out-ofpocket costs), respondents aged $19-34$ had more than 3.5 times the odds of borrowing (adjusted odds ratio [OR] 3.7, 95\% CI 2.3-5.7) compared to those aged 45-54 (Table 2). Respondents aged more than 54 had less than half the odds of borrowing compared to those aged 45-54. Having poor selfreported health status was associated with substantially higher odds of borrowing (adjusted OR 7.7, 95\% CI 3.7-15.9) compared to having excellent health. Insurance coverage was also important: respondents who reported having either government drug insurance or no drug insurance had twice the odds of borrowing to pay out-of-pocket costs for prescriptions (adjusted OR 2.0, 95\% CI 1.4-2.9) compared to those with employer-sponsored drug insurance. Other factors associated with increased adjusted odds of borrowing were having 2 or more chronic conditions, having a household income less than $\$ 40000$ and spending more money out of pocket on prescription drugs.

\section{Extent of out-of-pocket costs among borrowers}

Among those who reported having borrowed money to pay for prescription drugs in the previous year $(n=6798)$, the largest group (an estimated 247397 [33.8\%], 95\% CI 28.1$39.5)$ borrowed money to pay for comparatively low drug costs, \$200 or less. Another estimated 195859 (26.8\%) 


\begin{tabular}{|c|c|c|}
\hline Variable & Unadjusted OR (95\% Cl) & Adjusted OR $(95 \% \mathrm{Cl})^{\star}$ \\
\hline \multicolumn{3}{|l|}{ Sex } \\
\hline Female & $1.7(1.3-2.4)$ & $1.3(1.0-1.8)$ \\
\hline Male & Reference group & Reference group \\
\hline \multicolumn{3}{|l|}{ Age, yr } \\
\hline $12-18$ & $0.9(0.5-1.6)$ & $2.7(1.2-6.5)$ \\
\hline $19-34$ & $1.8(1.2-2.6)$ & $3.7(2.3-5.7)$ \\
\hline $35-44$ & $1.1(0.7-1.9)$ & $2.1(1.2-3.9)$ \\
\hline $55-64$ & $0.9(0.6-1.5)$ & $0.5(0.3-0.9)$ \\
\hline $65-74$ & $0.7(0.4-1.3)$ & $0.2(0.1-0.4)$ \\
\hline$\geq 75$ & $0.6(0.3-1.2)$ & $0.1(0.1-0.2)$ \\
\hline $45-54$ & Reference group & Reference group \\
\hline \multicolumn{3}{|l|}{ Self-reported health status } \\
\hline Very good & $2.0(1.1-3.7)$ & $1.5(0.8-2.7)$ \\
\hline Good & $5.3(3.1-9.1)$ & $3.0(1.7-5.3)$ \\
\hline Fair & $11.8(7.0-19.9)$ & $4.5(2.4-8.4)$ \\
\hline Poor & $26.0(14.2-47.6)$ & $7.7(3.7-15.9)$ \\
\hline Excellent & Reference group & Reference group \\
\hline \multicolumn{3}{|l|}{ No. of chronic conditions } \\
\hline 1 & $2.7(1.6-4.3)$ & $1.8(1.1-3.1)$ \\
\hline 2 & $4.0(2.7-6.0)$ & $2.2(1.4-3.5)$ \\
\hline 3 & $6.3(3.9-10.0)$ & $2.4(1.4-4.2)$ \\
\hline$\geq 4$ & $11.9(7.6-18.6)$ & $4.5(2.5-8.1)$ \\
\hline 0 & Reference group & Reference group \\
\hline \multicolumn{3}{|l|}{ Total household income, \$ } \\
\hline$<20000$ & $7.3(4.0-13.4)$ & $3.9(1.9-8.2)$ \\
\hline $20000-39999$ & $5.3(2.9-9.5)$ & $2.7(1.3-5.4)$ \\
\hline $40000-59999$ & $2.9(1.6-5.4)$ & $1.9(0.9-3.9)$ \\
\hline $60000-79999$ & $2.1(1.1-4.1)$ & $1.5(0.7-3.2)$ \\
\hline $80000-99999$ & $1.8(0.9-3.5)$ & $1.3(0.6-2.6)$ \\
\hline $100000-149999$ & $1.1(0.5-2.4)$ & $0.9(0.4-1.9)$ \\
\hline$\geq 150000$ & Reference group & Reference group \\
\hline \multicolumn{3}{|l|}{ Education } \\
\hline Secondary school & $0.8(0.6-1.2)$ & $0.8(0.5-1.3)$ \\
\hline Postsecondary school & $0.7(0.5-1.0)$ & $0.8(0.5-1.2)$ \\
\hline Less than secondary school & Reference group & Reference group \\
\hline \multicolumn{3}{|l|}{ Prescription drug insurance } \\
\hline Association plan and private plan & $1.6(1.0-2.8)$ & $1.7(1.0-3.0)$ \\
\hline Government plan & $2.9(2.1-3.9)$ & $2.0(1.4-2.9)$ \\
\hline None & $3.5(2.5-5.0)$ & $2.3(1.5-3.5)$ \\
\hline Employer plan & Reference group & Reference group \\
\hline \multicolumn{3}{|c|}{ Out-of-pocket prescription drug spending in prior year, \$ } \\
\hline 0 & $0.1(0.0-0.2)$ & $0.1(0.0-0.2)$ \\
\hline $201-500$ & $2.7(1.9-3.8)$ & $2.5(1.7-3.7)$ \\
\hline $501-1000$ & $3.7(2.6-5.3)$ & $3.6(2.3-5.7)$ \\
\hline$>1000$ & $5.1(3.2-8.0)$ & $3.8(2.2-6.6)$ \\
\hline $1-200$ & Reference group & Reference group \\
\hline
\end{tabular}


(95\% CI 21.2-32.4) borrowed money to pay out-of-pocket drug costs of \$201-\$500. Finally, an estimated 143601 (19.6\%) (95\% CI 14.7-24.6) and 113303 (15.5\%) (95\% CI 11.8-19.2) of those who reported borrowing money did so for out-of-pocket drug costs of $\$ 501-\$ 1000$ and more than $\$ 1000$, respectively.

\section{Interpretation}

The out-of-pocket costs associated with having to pay for prescription drugs have important implications for Canadians. We found that $2.5 \%$ of Canadians, or an estimated 731000 people, borrowed money to pay for the out-of-pocket costs of their prescription drugs in the previous year. This represents another form of compensatory behaviour to deal with drug charges on top of the substantial rates of costrelated nonadherence to prescription medications and tradeoffs with other expenditures patients in Canada report. ${ }^{11}$ Furthermore, we found that borrowing was most common among groups who also display these other compensatory behaviours, including younger people, those with lower self-reported health, those with government or no drug insurance, and those with lower household income. ${ }^{11}$ Notably, we found that borrowing to pay for prescription drugs occurred at all levels of out-of-pocket costs, and over $60 \%$ of borrowing reported by our respondents in the previous year occurred for out-ofpocket costs of $\$ 500$ or less.

Our findings are consistent with other research on costrelated nonadherence and associated compensatory behaviours. ${ }^{6,9,11}$ Studies from the US have shown cost-related nonadherence to be associated with food insecurity and cutting back on necessities. ${ }^{10,16}$ This is sobering in light of the fact that most drugs for which patients need to make these tradeoffs are relatively inexpensive. ${ }^{10,11}$ Our findings suggest that the consequences of high drug costs are more extensive than just reducing adherence to medicines; there are likely impacts on other aspects of patients' quality of life.

There is an opportunity for health care providers to intervene and initiate conversations with patients to help support those who are at greatest risk of cost-related nonadherence and the attendant compensatory behaviours. Prior research suggests that patients who have high levels of trust in their health care providers tend to be at lower risk for cost-related nonadherence..$^{30}$ Although many physicians feel they are not well positioned to manage conversations about medication costs, many health care providers also believe it is their responsibility to engage patients in these conversations. ${ }^{31,32}$ Prescribers can improve medication affordability for patients by staying up to date on drug costs, prescribing the most costeffective alternative, frequently reviewing medication regimens for opportunities to deprescribe and prescribing generic drugs. $^{31,33}$

Multiple policy interventions can be used to address the negative impacts on patients who are struggling to pay for prescription drugs. ${ }^{34}$ For example, some provinces have recently implemented policy changes to help address costrelated nonadherence: Ontario implemented a pharmacare program for youth under the age of 25 who lack private prescription drug insurance, and British Columbia has reduced or eliminated public drug insurance deductibles for families earning less than $\$ 45000$ per year. ${ }^{36,36}$ Future studies should investigate the impact of such changes on both cost-related nonadherence to prescription medications and borrowing behaviours.

\section{Limitations}

Like other survey-based study designs, our results are based on patient self-report, which is potentially susceptible to recall bias and social desirability bias. If recall bias had an effect on our findings, this likely would have resulted in conservative estimates. ${ }^{37} \mathrm{We}$ were unable to ask more specific questions about the kind of borrowing patients engaged in (e.g., from family and friends, a financial institution, or a payday loan or cash advance lender, against a mortgage or home, on a credit card) and were unable to assess how respondents interpreted the question or to gauge the amount of money that might have been borrowed.

\section{Conclusion}

Our findings show that many Canadians have borrowed money to pay for out-of-pocket prescription drug costs. Borrowing occurred for relatively inexpensive drugs as well as more costly ones and disproportionately affected vulnerable groups such as those who have low income, those with poor self-reported health status and those who lack prescription drug insurance. In Canada, some provinces are already taking steps to implement policy changes to help these more vulnerable groups address cost-related nonadherence to prescription medications and other associated behaviours. Future research should investigate the impacts of such changes that could increase equity in access to prescription drugs.

\section{References}

1. Daw JR, Morgan SG. Stitching the gaps in the Canadian public drug coverage patchwork? A review of provincial pharmacare policy changes from 2000 to 2010. Health Policy 2012;104:19-26.

2. Kratzer J, McGrail K, Strumpf E, et al. Cost-control mechanisms in Canadian private drug plans. Healthc Policy 2013;9:35-43.

3. National health expenditure trends, 1975 to 2016. Ottawa: Canadian Institute for Health Information; 2016.

4. Hennessy D, Sanmartin C, Ronksley P, et al. Out-of-pocket spending on drugs and pharmaceutical products and cost-related prescription non-adherence among Canadians with chronic disease. Health Rep 2016;27:3-8.

5. Briesacher BA, Gurwitz JH, Soumerai SB. Patients at-risk for cost-related medication nonadherence: a review of the literature. 7 Gen Intern Med 2007;22:864-71.

6. Law MR, Cheng L, Dhalla IA, et al. The effect of cost on adherence to prescription medications in Canada. CMA7 2012;184:297-302.

7. Khalil Zadeh N, Robertson K, Green JA. "At-risk" individuals' responses to direct to consumer advertising of prescription drugs: a nationally representative cross-sectional study. BM7 Open 2017;7:e017865.

8. Waisel DB. Vulnerable populations in healthcare. Curr Opin Anaesthesiol 2013 ; 26:186-92.

9. Goldsmith LJ, Kolhatkar A, Popowich D, et al. Understanding the patient experience of cost-related non-adherence to prescription medications through typology development and application. Soc Sci Med 2017;194:51-9.

10. Bengle R, Sinnett S, Johnson T, et al. Food insecurity is associated with costrelated medication non-adherence in community-dwelling, low-income older adults in Georgia. 7 Nutr Elder 2010;29:170-91.

11. Law MR, Cheng L, Kolhatkar A, et al. The consequences of patient charges for prescription drugs in Canada: a cross-sectional survey. CMA7 Open 2018;6:E63-70

12. Kennedy J, Morgan S. Cost-related prescription nonadherence in the United States and Canada: a system-level comparison using the 2007 International Health Policy Survey in Seven Countries. Clin Ther 2009;31:213-9. 
13. Lee A, Morgan S. Cost-related nonadherence to prescribed medicines among older Canadians in 2014: a cross-sectional analysis of a telephone survey. CMA7 Open 2017;5:E40-4.

14. Kennedy J, Morgan S. A cross-national study of prescription nonadherence due to cost: data from the Joint Canada-United States Survey of Health. Clin Ther 2006;28:1217-24

15. Tamblyn R, Eguale T, Huang A, et al. The incidence and determinants of primary nonadherence with prescribed medication in primary care: a cohort study. Ann Intern Med 2014;160:441-50.

16. Heisler M, Wagner TH, Piette JD. Patient strategies to cope with high prescription medication costs: Who is cutting back on necessities, increasing debt, or underusing medications? 7 Behav Med 2005;28:43-51.

17. Soumerai SB, Pierre-Jacques M, Zhang F, et al. Cost-related medication nonadherence among elderly and disabled Medicare beneficiaries: a national survey 1 year before the Medicare Drug Benefit. Arch Intern Med 2006;166:1829-35.

18. Altice CK, Banegas MP, Tucker-Seeley RD, et al. Financial hardships experienced by cancer survivors: a systematic review. 7 Natl Cancer Inst 2016;109:pii: djw205.

19. Huntington SF, Weiss BM, Vogl DT, et al. Financial toxicity in insured patients with multiple myeloma: a cross-sectional pilot study. Lancet Haematol 2015;2:e408-16.

20. Essue B, Kelly P, Roberts M, et al. We can't afford my chronic illness! The out-of-pocket burden associated with managing chronic obstructive pulmonary disease in western Sydney, Australia. 7 Health Serv Res Policy 2011;16: 226-31.

21. Martin KR, Shreffler J, Schoster B, et al. Coping with prescription medication costs: a cross-sectional look at strategies used and associations with the physical and psychosocial health of individuals with arthritis. Ann Behav Med 2012;44: 236-47.

22. Banegas MP, Guy GP Jr, de Moor JS, et al. For working-age cancer survivors, medical debt and bankruptcy create financial hardships. Health Aff (Millwood) 2016;35:54-61.

23. Kennedy J, Tuleu I, Mackay K. Unfilled prescriptions of Medicare beneficiaries: prevalence, reasons, and types of medicines prescribed. 7 Manag Care Pharm 2008;14:553-60.

24. Madden JM, Graves AJ, Zhang F, et al. Cost-related medication nonadherence and spending on basic needs following implementation of Medicare Part D. 7AMA 2008;299:1922-8.

25. Canadian Community Health Survey (CCHS) rapid response January-Zune 2016 prescriptions - cost-related non-adherence. Ottawa: Statistics Canada; 2016. Available: http://www23.statcan.gc.ca/imdb/p3Instr.pl? Function=assembleInstr \&Item_Id=299879 (accessed 2017 Oct. 13).

26. Canadian Community Health Survey (CCHS) - annual component. Ottawa: Statistics Canada; 2015. Available: http://www23.statcan.gc.ca/imdb/p2SV. pl?Function=getSurvey\&Id=259374 (accessed 2018 Aug. 28).

27. Horton NJ, Lipsitz SR. Multiple imputation in practice. Am Stat 2001;55: 244-54.

28. Berglund P. An introduction to multiple imputation of complex sample data using SAS® 9.2 [paper 265-2010]. Proceedings from the SAS Global Forum 2010; 2010 Apr. 11-14; Seattle (WA). Available: http://support.sas.com/resources/ papers/proceedings10/265-2010.pdf (accessed 2017 Sept. 14).

29. Bootvar user guide (version 3.2 - SAS). Ottawa: Statistics Canada; 2010.

30. Piette JD, Heisler M, Krein S, et al. The role of patient-physician trust in moderating medication nonadherence due to cost pressures. Arch Intern Med 2005; $165: 1749-55$

31. Alexander GC, Casalino LP, Meltzer DO. Physician strategies to reduce patients' out-of-pocket prescription costs. Arch Intern Med 2005;165:633-6.
32. Alexander GC, Casalino LP, Tseng CW, et al. Barriers to patient-physician communication about out-of-pocket costs. 7 Gen Intern Med 2004:19:856-60.

33. Brown GD, Hunter WG, Hesson A, et al. Discussing out-of-pocket expenses during clinical appointments: an observational study of patient-psychiatrist interactions. Psychiatra Serv 2017;68:610-7.

34. Tang KL, Ghali WA, Manns BJ. Addressing cost-related barriers to prescription drug use in Canada. CMA7 2014;186:276-80.

35. Learn about OHIP+. Ontario.ca (Government of Ontario); [updated 2018 Sept. 11]. Available: https://www.ontario.ca/page/learn-about-ohip-plus (accessed 2018 Feb. 27).

36. Budget 2018: working for you. Government of British Columbia; 2018. Available: http://bcbudget.gov.bc.ca/2018/highlights/2018_Highlights.pdf (accessed 2018 Feb. 27).

37. Evans C, Crawford B. Patient self-reports in pharmacoeconomic studies. Pharmacoeconomics 1999;15:241-56.

Affiliations: Centre for Health Services and Policy Research (Kolhatkar, Cheng, Law), School of Population and Public Health; School of Population and Public Health (Morgan), University of British Columbia, Vancouver, BC; Faculty of Health Sciences (Goldsmith), Simon Fraser University, Burnaby, BC; Health Quality Ontario (Dhalla); Li Ka Shing Knowledge Institute (Dhalla), St. Michael's Hospital; Institute for Clinical Evaluative Sciences (Dhalla), Toronto, Ont.; Division of Clinical Pharmacology and Toxicology (Holbrook), Department of Medicine, McMaster University, Hamilton, Ont.

Contributors: Ashra Kolhatkar drafted the manuscript, and Lucy Cheng, Steven Morgan, Laurie Goldsmith, Irfan Dhalla, Anne Holbrook and Michael Law critically revised the manuscript for important intellectual content. All of the authors contributed substantially to the study conception and design, and analysis and interpretation of the data, approved the final version to be published and agreed to be accountable for all aspects of the work.

Funding: This analysis was funded by Operating Grant MOP-126020 (principal investigator: Michael Law) and Foundation Scheme Grant FDN-148412 (principal investigator: Michael Law) from the Canadian Institutes of Health Research. Michael Law received salary support through a Canada Research Chair in Access to Medicines and a Michael Smith Foundation for Health Research Scholar Award.

Disclaimer: Any opinions or conclusions expressed in this publication do not necessarily represent the opinions or conclusions of Health Quality Ontario. No endorsement is intended or should be inferred. This study was supported by ICES, which is funded by an annual grant from the Ontario Ministry of Health and Long-Term Care (MOHLTC). The opinions, results and conclusions reported in this article are those of the authors and are independent from the funding sources. No endorsement by ICES or the MOHLTC is intended or should be inferred.

Supplemental information: For reviewer comments and the original submission of this manuscript, please see www.cmajopen.ca/content/6/4/ E544/suppl/DC1. 